\title{
Scientific and Methodic Basis for Monitoring of Professional Readiness of the Future Teachers to Communicative Language Development of Preschool Children in a Dialogue of Cultures
}

\author{
Neonila V. Ivanova \\ Galina P. Zakharova \\ Tatiana S. Guseva \\ Marina Yu. Deryabina \\ Svetlana V. Veliyeva
}

Tatyana N. Semenova

Nadezhda N. Vasileva

Chuvash State Pedagogical University named after I.Y. Yakovlev, 428032, Cheboksary, Russia

Email: ivanovaneonila@mail.ru

\section{Doi:10.5901/mjss.2015.v6n2s3p50}

\section{Abstract}

The urgency of the problem under investigation is due to the need to develop innovative technologies and approaches to the professional development of students and their optimal willingness to solve the goals and objectives of bilingual education of preschool children in a dialogue of cultures and multilingualism. In this case there is a particularly acute problem of scientific and methodic support for monitoring of their readiness for communicative and language development of bilingual preschool children. The article aims at disclosing the content and theoretical basis for monitoring of professional readiness of students to communicative language development of bilingual children in the profile "Pre-school education" in the Chuvash Republic. The major approaches to the study of the problem are systematical, personal, activity, polysubject (dialogic), culturological, ethnopedagogical. Overall the results suggest the viability of the proposed scientific and methodic support for monitoring of professional readiness of students in the profile "Pre-school education." The article's materials may be useful in identifying the professional readiness of the future teachers of pre-school education to the communicative and language development of preschool children in the educational system of higher education.

Keywords: vocational training; professional readiness; communicative and language development; monitoring; bilingual children; competence-based approach.

\section{Introduction}

\subsection{Relevance of the research}

The Law on Education of the Russian Federation, Federal State Educational Standard of preschool education, teacher's professional standard and other regulations require universities to prepare professionals who are able to solve fully and comprehensively the problems of communicative and language development of preschool children and their bilingual identity with the regional component of education. Despite the fact that new Federal State Educational Standards of higher education are introduced in all the universities, which provide bachelor's and master's degrees, have not yet been generalized organizational and methodic aspects for monitoring of graduates' readiness to the communicative and language development of preschool children in a bilingual and dialogic cultures. Due to the high requirements for the qualification of teachers and their responsibility for the results of labor, the criteria for evaluating their professional readiness for pedagogical activity, in particular for the communicative language development of bilingual preschool children become complicated. In the Federal State Educational Standards of higher education the regional component is proclaimed as a key and important condition for training future teachers, which involves consideration of such defining 
features of the region's culture, as multi-ethnicity, poly-confessionality, dialogue of cultures, cultural relativism, tolerance, openness, ability to cultural adaptation, etc. This is supported by studies of G.P. Zakharova, who writes that the Russian education is built on the principle of the dialectical unity of national, federal and global components. This promotes the formation of each child's ethnic identity (Zakharova, 2014). In this ever-changing multicultural society national cultures and regional educational systems develop and cultural identity of each child is taking place . In this regard, many researchers have noted that in the process of development the child learns a particular cultural identity. However culture conformity of multicultural environment of its formation and development implies cultural poly-identity. For example, there are more than a hundred ethnic groups in Russia and all of them are represented in the structure of education. Therefore, the education according to its content is national, poly-cultural, and as for the means (forms, methods, technologies) it is multicultural simultaneously. Culture was originally developed in the mode of self-organization and education is developed on the basis of tolerance, equality and integration of cultures. In this context, G.P. Zakharova speaks of polychrone cultural space, which she explains as operation in a particular time and space of subjects (individuals or social communities) of different cultural ages. And that, in her opinion, sets a unique context for the functioning of the educational system: if education qualifies for culture genesis functions, it should be culture congruous. But as every modern culture is polychrone, the educational model has no right to be unified and monolithic - taking into account its participants' cultural age, it should be a variable one. The principle of variability of pre-school education reflects such a feature of modern culture as multiculturalism and being polychrone (Zakharova, 2014).

\subsection{The experience of the Chuvash Republic}

On the territory of the Chuvash Republic for many centuries the interaction of different cultures took place, so it has the striking features of "border culture". The results of the National Population Census in Chuvashia showed that 115 nationalities representatives live here. However, there are four most numerous ethnic groups: Chuvash, Russian, Tatar and Mordvinians. According to the same data, the following nationalities representatives live in Chuvashia: Belarussians, Armenians, Azerbaijanis, Tajiks, Gypsies, Uzbeks, Germans, Moldavians, Udmurts, Jews, Bashkirs, Georgians, Kazakhs, Chechens, Greeks, Poles, Arabs, Koreans, Lithuanians, Estonians, Vietnamese, Chinese, British, Japanese, Americans and others. The most common languages in the country are Russian, Chuvash, English, Tatar, German, Mordovian, French, Armenian, and language of the deaf. Rare languages, but used in speech are Rutul, Selkup, Thai, Evenksky, Nenets, Vepsian, Udi, Abaza, Adyghe, Amharic, Chukchi, Bengali and others.

Due to the fact that the language of the deaf in our country is one of the common languages, it becomes apparent that it is necessary to strengthen the correctional (defectology) training of future teachers.

\subsection{Literature Review}

Modern preschools in Chuvash Republic are characterized by polyethnicity, causing preschools' workers certain difficulties in the organization of upbringing and educational work with children as well as in the communicative language development of bilinguals. They have to take into account the cultural and linguistic specificity of child development and to train a second language based on comparative-typological characteristics of the languages in contact, their identity and the grammatical structure of the interfering influence of the native (Chuvash) language studied (Guseva, 2011; Ivanova, 2014). Among the students, who study on the profile "Preschool Education", dominate Chuvash-speaking students with the knowledge of the Russian language. Then - Russian-speaking students, who do not speak Chuvash language, Tatarspeaking students with the knowledge of Russian language. There are Mari students with the knowledge of the Russian language, Turkmens with poor knowledge of the Russian language, and others. The most common mother tongues of students are Russian, Chuvash, Tatar and Mordovian languages. However, among the non-native languages most widely used English, German, French.

According to the results of numerous studies of bi- and multilingualism held by G.A. Anisimov (2006), T.S. Guseva (2011), N.V. Ivanova (2014) and others, an incomplete type of bilingualism is typical for our country, which is characterized by receptivity / reproduction, the confusion of languages, mediation, subordinativeness / coordinativeness. For example, in rural areas bilingualism is passive, in cities bilingualism is on the contrary dynamic. With regard to national educational institutions bilingualism is considered within the framework of sequential bilingualism (Ivanova, 2013).

Considering the fact, that bilingual children joining another language complicates and slows down the development of speech (from minor irregularities in the sound design to the violations in the lexical and grammatical structure), T.N. Semenova's approach to the consideration of the teacher's readiness to work on the development and correction of 
speech of preschool children with the help of ethnopedagogics in a multiethnic environment is very interesting (Semenova, 2014). So, T.N. Semenova in defectological readiness of the future teacher identifies three interrelated components combined into an integral whole. Firstly, the motivational evaluative component, which implies future teachers-defectologists' awareness of the place and role of folk pedagogy in education of preschool children with speech disorders. Secondly, the cognitive component, which implies the existence of future teachers vast range of scientific knowledge about the methodology and methods of work on the development and correction of speech by means of folk pedagogy. Thirdly, the activity component, expressed in the future teachers' formation of professionally significant competences required for the application of ethnopedagogical means in training and education of preschool children with speech disorders (Semenova, 2014).

Thus, it becomes evident that cultural and anthropological approach in the training of future teachers to the communicative and language development of bilingual preschool children should become backbone.

The use of competence-based approach in today's higher education strengthens focus on educational outcomes, which includes the development of science-based system for monitoring the quality of training of future teachers for their professional activities in a dialogue of cultures.

\section{Methodological Framework}

Reforming of higher education, dynamically changing socio-economic and socio-cultural conditions of the development of modern society led to the need of scientific and methodic support for monitoring of professional readiness of students to communicative language development of bilingual preschool children. As rightly pointed out in the order of the Ministry of Labor and Social Protection of the Russian Federation dated October 18, 2013 № 544n, training of future teachers should be redirected to the new realities of the education system - the need for professionals who are ready for change, mobile, capable of non-standard employment actions, responsible and independent in decision-making, and most importantly "constantly showing their students how to learn."

The scientific and methodological basis for monitoring the professional readiness to communicative and language development of bilingual preschool children made traditional and innovative concepts of training teachers in humanitarian institutions of higher education. In particular - competence-based, personality-oriented, cultural, anthropological, systemoptimizational, axiological, personality and activity, acmeological, system-holistic approaches, the concept of quality education system diagnostics, examination of the concept of human education, forecasting methods, and others.

In the opinion of Ivanova N.V. training involves purposeful, systematic and controlled process, the result is the formation of professional readiness composed of professionally significant competences of teachers in the relevant field of language development of bilingual preschool children (Ivanova, 2013). This understanding of training in our study becomes a key one. Therefore, monitoring of professional readiness of the future teachers to communicative language development of bilingual preschool children at the university should be focused not only on the assimilation of professional competence, but also on the professionally significant personal qualities, which are essential components of professional readiness and professionalism. The term "professional readiness" in the scientific literature is used to express the imposed requirements to the teacher. Along with this concept the term "professional qualifications" is used. In our opinion, professional readiness of the teacher is a central concept that expresses the ultimate goal of education and is a complex, systemic, holistic education, the result of the interaction of all educational systems operating in high school (Slastenin, 2003).

Often the term "professional qualifications" is understood as a set of mental and psycho-physiological characteristics of a person needed to succeed in their chosen profession and includes the knowledge, skills and abilities. Therefore, distinguishing of psychological, scientific and theoretical, psycho-physiological, physical and practical readiness of the teacher in its composition is justified.

The majority of scientists believe that readiness is a "predisposition of the subject to focus its activities in a certain way," "it is a special state of mind and a relatively stable personality characteristics" (Slastenin, 2002).

Consequently, professional readiness of the teacher to communicative language development of bilingual preschool children in various educational institutions is the main indicator of their training, the quality of their personality and factor in the success of their professional activities.

Psychological readiness for professional work is often considered as a mental state that is formed in the course of training. Therefore, it is considered in two aspects: 1) as a factor and condition for successful vocational education; 2) as a result of training.

In the opinion of S.V. Veliyeva, the psychological content of the concept of "professional readiness" is based on individual characteristics such as its ability to professionally significant qualities (Veliyeva, 2014). 
Professional readiness of the teacher is a complex, integrative personal formation (Veliyeva, 2014) in the framework of fundamental humanitarian settings. Therefore, when developing a monitoring system of professional readiness of the future teachers to communicative language development of bilingual children is very important to use appropriate means to identify personality characteristics and the level of psychological readiness. For psychological readiness and personal qualities are stable, steady properties acting consistently and are an important prerequisite of successful professional and innovative work of the teacher (Veliyeva, 2014).

Professionalism of the teacher is a concentrated indicator of his professional readiness and his personality-activity essence. This qualitative characteristic of professional readiness, in the opinion of many researchers, shows the level of the development of the teacher's competence. Therefore, teacher's professionalism, which solves the problem of communicative language development of bilingual children will be expressed by the formation of their competence in matters of bi- and polylingual education of preschoolers, by the degree of ownership of theoretical and practical knowledge and methods of solving professional problems caused by civil responsibility, maturity and professional duty (Gabdulkhakov , 2009). However, the measure of professionalism in the training of teachers in high school is almost impossible.

According to V.F. Gabdulkhakov (2009) professionalism is the result of the creative pedagogical work of the teacher, carried out at a very high level of labor productivity. We believe that professional teacher should know what and how to teach and raise a bilingual child, and also be able to transfer him from one state to another. In the structure of professionalism they distinguish (in particular, Gabdulkhakov V.F.) three interrelated components - professional knowledge, professional communication, professional self-improvement. However, if one of these components is not formed, the teacher's professionalism will be ill-formed as a whole (Gabdulkhakov, 2010).

Therefore, the main and most important task of training future teachers to communicative language development of bilingual preschool children is the formation of all the necessary competencies to develop their professionalism in future practice.

By professional readiness of teachers to communicative language development of bilingual preschool children, we understand the integral phenomenon that combines pedagogical, psychological, linguistic, linguodidactical, cultural, anthropological, creative readiness and willingness to carry out educational activities in an inclusive and innovative process.

Idealized personal and professional qualities that make professional readiness of the teacher to communicative language development of bilingual preschool children, can be represented as a profession diagram or passport of competencies.

Substantial characteristics of a graduate's professional readiness defines a set of competencies that are formed as a result of studying the corresponding cycles of academic disciplines, united in educational modules that are built on the basis of subject-activity approach. The model of a graduate as a qualitative characteristic of a result of education is introduced on the basis of competence-based approach. A key component of competence is knowledge. But today, the role and importance of knowledge in the modern teacher education is justified by the change of its functions adaptational, informational, action-developing. Adaptational aspect of the content of knowledge is linked with the goal setting (for what purpose the knowledge is developed, feasibility of its mastering from the standpoint of value-semantic implications for the future profession is being revealed). Informational function provides the volume and the relevance of knowledge. Activity-developing function characterizes the quality of the mastered knowledge in its practical importance. In the context of these values of contemporary knowledge, its role in activity-model of professional and social activity of the future teacher is being changed.

However, according to G.P. Zakharova (2014), M. Yu. Deryabina (2009), it is not knowledge addressed in the past "what and how to do" (instructional model of learning), but it is competence, facing the future (creative (innovative) learning model), rising to the result of the pedagogical process. Appeal to the results of the pedagogical process enhances learning practical orientation, its subject-practical orientation, emphasizes the role of experience (studentcentered, subject-directional, dialogic) to solve specific educational tasks. The prospects of this direction we associate with the actualization of students' skills for self-organization of activities (educational, cultural, educational, and others.) as the basis for the success of the professional competence of the future teacher (Zakharova, 2014; Deryabina, 2009).

There are three interrelated components in the structure of pedagogical activity: structural, organizational and communicative. Therefore, the future teacher should possess the skills of structural, organizational (management) and communicative activities.

The most acceptable, in our opinion, is the concept of V.A. Slastenin to identify the key components of professional readiness of the future teachers to communicative language development of bilingual preschool children (Slastenin, 2003). Therefore, the key components of professional readiness of the teacher to communicative language development 
of preschool children in a dialogue of cultures are the following interrelated components: motivational-evaluative, cognitive and activity, which are formed, developed and improved with the scientific and theoretical and practical training at the university.

Nowadays, there is no uniformity in the understanding of bilingual competence, as well as a clear separation of the concepts of "competence" and "competency". Competence is viewed as a predetermined requirement for the training of future teachers needed for communicative language development of bilingual children, and competency - as a personal quality, which manifests itself in its ability to carry out this work (Ivanova, 2013).

The use of a competence-based approach in today's higher education reinforces the emphasis on learning outcomes.

A recognized authority in the field of modernization of European education Adam S. (2008), having carried out the analysis of various definitions of "learning outcomes", recommends to identify the results of training related to the achievements of the student. Therefore, the system of monitoring of the quality of professional readiness of the future teachers for communicative and language development of children in situations of bilingualism should be focused on the progress made by the student, and not the learning objectives, which are caused by the intentions of the teacher.

Competence-based approach in the process of training future teachers forces us to abandon traditional methods of monitoring learning outcomes that take into account a set of didactic units and the number of hours. Methods focused on formed competencies, should be used in the monitoring system of professional readiness of future teachers.

Thus, developing the basic tools, methods and ways of monitoring of professional readiness of the future teachers to communicative language development of preschool children in the conditions of the dialogue of cultures it is necessary to shift the focus from the content of the training on the result.

The project TUNING allocated two types of learning outcomes: minimum requirements and expected learning outcomes. Here are some examples that illustrate the use of the competence format for the introduction of expected learning outcomes according to Federal State Educational Standards of higher education direction 050100 Teacher education profile "Pre-school education." For example, the learner is able to demonstrate a culture of thinking, the ability to generalize, analyze, perception of information, goal setting and choice of ways to achieve it (CC); the ability to analyze the ideological, social and personal significant philosophical problems (CC 2); the ability to understand the importance of culture as a form of human existence and to be guided in its work by modern principles of tolerance, dialogue and collaboration (CC 3); willingness to tolerant perception of social and cultural differences, respectful and caring attitude for the historical heritage and cultural traditions (CC 14); the ability to identify and take advantage of regional cultural educational environment for the organization of cultural and educational activities, and others.

System-optimization approach to the training of future teachers (Lukyanova, 2004), which is a complex system of training teachers for communicative and language development of bilingual preschool children on the basis of its optimization is very important for our work. This approach implies the possibility of choosing the optimal education program among available variable educational programs in conformity with the needs of students, their prospects for professional growth, focused on the formation of their professional competence taking into account the needs of the region.

Thus, the professional readiness of the future teacher for communicative and language development of bilingual preschool children on the basis of studied approaches reflects his professional competence, which appears to us as a set of universal values, professional and humanistic orientation, formation of professional and personal qualities, knowledge of modern technologies, the development of communicative speech skills in bilingual children. Professional competence of the future teacher for the speech development of bilingual children contains regionally-mediated competencies.

\section{Results and Discussions}

In accordance with the modern understanding of the quality of education and the concept of humanitarian examination of the results monitoring of professional readiness of the future teachers to communicative language development of bilingual children is aimed at determining the dynamics of professional and personal growth of students, taking into account their characteristics, attitudes towards their future profession, achieved results and correction of the contenttechnological support in their training.

As the basis for the design of monitoring of professional readiness of the future teacher for communicative and language development of bilingual children we took a five-component structure of personality:

1) orientation of the person (settings, motives, interests, desires, expectations, etc.);

2) professional competency (knowledge, skills or competences);

3) personal qualities (reflexivity, creativity, attention, observation, determination, tolerance, sociability, 
independence, hard work, etc.);

4) professionally significant physiological properties (energetics, neuroticism, extroversion, visual-motor coordination, reactivity, etc.)

5) bilingual competency (a set of communicative and linguistic competence of native and non-native languages). behavioral.

The main criteria of formation of students' professional competency are the cognitive, motivational, affective and

Monitoring of professional readiness of the future teachers to communicative language development of bilingual children is implemented at two levels: internal and external. Internal level involves monitoring of professional readiness within the institution and is based on the following criteria: level of pedagogical reflection and self-education of a student; motives of mastering the teaching profession; satisfaction with the educational process; professional and personal growth; relevance of research works of students in the field of education and upbringing of the university and the region; development of social and cultural environment of the university. External level of monitoring aims to study: 1) the demand for pre-school education in the region in professionally-trained teachers for communicative and language development of bilingual children, 2) indicators of competitiveness and mobility of graduates in the market of educational services and educational activities.

In accordance with the requirements to the organization of monitoring and evaluation, compliance with which is considered to be necessary in the context of result-oriented competence-based approach, the monitoring system of professional readiness of the future teacher for communicative and language development of bilingual preschool children contains adequate methods of monitoring and evaluating material in the phase of results formulation. The most important condition of monitoring is the complexity and functionality of traditional forms of control (current, landmark, intermediate and final).

Monitoring of the quality of training is focused on the following objectives: 1) control using a set of assessment means for students' knowledge acquisition processes, skills, general and professional competences; 2) management of the vocational training.

Selection of individual traditional and innovative forms of control is carried out in accordance with the technology of teaching disciplines, teaching styles and the feasibility of the implementation of various forms of control. Thus, the system of monitoring of the level of future teachers' professional readiness for communicative and language development of bilingual children involves the following traditional forms of control - oral questioning (tests, exams, interview, colloquium, etc..), written assignments (essays, tests, reports, essays tests, term papers, research reports on educational practices, reports on the Research Works of Students et al.), with the help of technical means of verification. Innovative assessment means such as: portfolio, presentation, a landmark certification tests, practical skills tests, questionnaire surveys and some others are very popular. These types of controls are used as a complex and independently as specific types of control. The rating system, realized in high school, is a good tool for the evaluation of professional readiness of the future teachers to communicative language development of bilingual children.

\section{Conclusion}

The content of the scientific and methodic support for monitoring of professional readiness of students to communicative language development of bilingual children in the profile "Pre-school education" in the Chuvash Republic, proposed in the article, complies with the following principles: conformity of the content of training to the general and disciplinary objectives of professional training; the unity of its substantial and procedural sides; structural integrity of the content; orientation of its content for the implementation of the systematic, personal, activity, polysubject (dialogic), cultural approaches. Some of the theoretical and practical aspects are studied and summarized, the scientific substantiation of organizational methods of monitoring of the future teachers' professional readiness to communicative language development of bilingual preschool children is given.

\section{References}

Adam, S. (2008). Learning outcomes: the state of affairs in Europe. New use of learning outcomes in the context of the Bologna process. Bologna Seminar Learning Outcomes Based Higher Education. Edinburgh 2122 February.

Anisimov, G. A. (2009). Speech development of a bilingual person in the light of the competence approach in philological education. Bulletin of the Chuvash State Pedagogical University I. Ya. Yakovlev. Cheboksary 3.

Deryabina, M. J. (2009). Professional and creative activity of the teacher of preschool educational institution. Cheboksary.

Federal Law of the Russian Federation of December 29, 2012 N 273-FZ "On Education in the Russian Federation", www.rg.ru/2012/ 
12/30/obrazovanie-dok.html

Federal State Educational Standard of Higher Professional Education (HPE GEF) in the direction 050100 Teacher education profile "Preschool Education" [electronic resource] - Access - URL: http: // www.petrsu.ru/Abit/doc_FG0S/050100.62.pdf

Gabdulhakov, V. F. (2009). Strategies for implementing the standards of the second generation in the Republic of Tatarstan. Standards and monitoring in education 1.

Gabdulhakov, V. F., Kayumova, A. M., Yusupova, G. F. (2010). The competence of the future teacher of preschool educational institution. Bulletin TSHPU $3:$ 206-212.

Gusev, T. S. (2011). Comparative analysis of the levels of development of phonetic and phonemic systems of Russian and Chuvash languages have Chuvash speaking preschoolers. Bulletin of the Chuvash State Pedagogical University I. Ya. Yakovlev. Cheboksary 4.

Guseva, T. S. (2011). Identify the level of language development in their native language to the top of mastering a second language at Chuvash speaking preschoolers. Bulletin of the Chuvash State Pedagogical University I. Ya. Yakovlev. Cheboksary 3.

Ivanova, N. V. (2013). Scientific aspects of training students in the formation of bilingual competence in preschool children in a multicultural environment. Bulletin of the Chuvash State Pedagogical University. I. Ya. Yakovlev $4: 72-76$.

Ivanova, N. V. (2013). Vocational training of students in the formation of bilingual competence in preschool children in a multicultural environment. International Journal of applied and basic research $6: 105-107$.

Ivanova, N. V. (2014). General approach to implementation national-regional component content of training of future specialists bilingual education preschool. Modern problems of science and education. 5-URL: http://www.science-education.ru/119-14923.

Ivanova, N. V. (2014). On the role of the comparative method for training in communicative language development of preschool children in a bilingual dialogue of cultures. Philology. Theory and Practice $2: 99-101$.

Ivanova, N. V., Smirnova, I. V. (2014). The concept of vocational training of students to communicative speech development of preschool children. Fundamental studies 5 : 352-355.

Lukyanov, M. I. (2004). Formation of professional readiness of the teacher to realization of personality oriented approach in teaching activities (Doctoral dissertation). Ulyanovsk.

Ministry of Labor and Social Protection of the Russian Federation dated October 18, 2013 № 544n "On approval of the professional standard" Teacher "(educational activities in the field of preschool, primary general, basic general, secondary education) (educator, teacher)"

Semenov, T. N. (2014). Formation of readiness of the future pathologists to use the potential of folk pedagogy in speech therapy work with preschool children. Moscow.

Semenov, T. N. (2014). Vocational training students to use ethnopedagogical funds in correctional and speech therapy work with children of preschool age. Bulletin of the Chuvash State Pedagogical University. I. Ya. Yakovlev 3.

Slastenin, V. A. (2002). Pedagogy. Moscow.

Slastenin, V. A. (2003). Introduction to the teaching axiology. Moscow.

Teacher professional standard. www.academy.edu.by/files/prof_standart_pedagoga.pdf

The results of the National Population Census 2010. http://www.regnum.ru/news/polit/1600066.html\#ixzz3LZHQy68K

Veliyeva, S. V. (2014). Formation of psychological readiness of the future teachers in the field of psychology to innovation. Moscow.

Zakharova, G. P. (2014). Culture-genesis function of preschool education: the development of innovation and problem solutions. Culturegenesis function of education: the development of innovative models. Cheboksary. 